\title{
Motility and Cytoskeletal Organization of Migrating Cerebellar Granule Neurons
}

\author{
Rodolfo J. Rivas and Mary E. Hatten \\ The Rockefeller University, New York, New York 10021-6399
}

\begin{abstract}
To characterize CNS neuronal precursor migration along astroglial fibers, we examined the motility of the migratory leading process and cytoskeletal-based mechanisms of locomotion of early postnatal mouse cerebellar granule neurons in vitro. To visualize the surface motility of the leading process, granule neurons were labeled with the fluorescent lipophilic dye, PKH-26, and imaged by time lapse fluorescence microscopy. The motile behavior and cytoskeletal organization of the migrating neuron had several distinctive features. As the migrating neuron moved along the glial fiber, the leading process rapidly extended, projecting up to $\mathbf{4 0}$ $\mu \mathrm{m}$, and retracted, withdrawing towards the cell soma. Broad lamellipodia were common along the entire length of the leading process, giving it a ruffled appearance. Within the cell soma, a cage-like distribution of microtubules encircled the nucleus and actin filaments formed a subcortical rim underneath the plasma membrane. Disruption of actin filaments with cytochalasin $B$ inhibited migration, suggesting involvement of actin subunit assembly in neuronal migration. Both microtubules and actin filaments were heavily concentrated in the leading process; the leading process did not show the development of a distinct actin-rich domain at its tip.
\end{abstract}

[Key words: neuronal migration, cytoskeleton, cell polarity, cerebellum]

In the developing mammalian brain, neuronal migration establishes the laminar pattern of cortical regions, ushering young neurons from ventricular zones where they are generated to the layers where they establish synaptic relationships (Ramon y Cajal, 1911; Sidman and Rakic, 1973). Although considerable progress has been made towards identifying the primary pathways for neuronal migration (Rakic, 1990; Gray and Sanes, 1991; O'Rourke et al., 1992; Hatten, 1993) and the adhesion systems that function in directed migration along the radial glial fiber system (Edmondson et al., 1988; Sanes, 1989; Fishell and Hatten, 1991; Fishman and Hatten, 1993), the cytoskeletal structures underlying the specialized motility of migrating neurons during CNS development remain uncharacterized.

\footnotetext{
Received Mar. 3, 1994; revised June 30, 1994; accepted July 28, 1994.

We gratefully acknowledge the advice of Drs. Gord Fishell and Renata Fishman and thank Dr. Fishell and Dr. Sharon Powell for reading the manuscript. Peter Peirce provided expert assistance with photomicrographs. This work was supported by NIH Postdoctoral Fellowship NS08834 (R.J.R.) and NIH Grant NS 15429 (M.E.H.)

Correspondence should be addressed to Mary E. Hatten, The Rockefeller University, 1230 York Avenuc, New York, New York 10021-6399.

Copyright (c) 1995 Society for Neuroscience 0270-6474/95/150981-09\$05.00/0
}

The cerebellar granule neuron has provided an experimental model for CNS migration, in part because the specialized movement of granule neurons along glial fibers can be reproduced in an in vitro system (Edmondson and Hatten, 1987; Hatten, 1990). During migration, the granule neuron is highly polarized in the direction of cell movement. The rostral portion of the elongated cell body tapers in the direction of migration into a thickened migratory leading process that extends along and wraps around the glial fiber (Rakic, 1971; Edmondson and Hatten, 1987). The saltatory movement of the neuronal cell soma, moving and pausing in regular intervals (Edmondson and Hatten, 1987), resembles the cyclic advance of migrating fibroblasts (Abercrombie et al., 1970; Abercrombie, 1980). This view is supported by the findings of Dunn and Heath (Dunn and Heath, 1976), who showed that while fibroblast locomotion is random on flat substrates, movement is oriented when the cells move on a thin-cylindrical substrate. In this model, the growing tip of the leading process would advance along the thin glial fiber by rapid extension and retraction of the leading process, analogous to the rapid advance and retreat of the fibroblast leading lamella, with a net movement in the direction of migration.

Two lines of evidence suggest a role for the cytoskeleton in neuronal motility along astroglial fibers. First, by correlated video and electron microscopy, a system of longitudinally oriented microtubules extends from a juxtanuclear basal body into the leading process (Gregory et al., 1988). The microtubule system has been proposed to underlie an oriented flow of membranous elements and vesicles from the soma into the leading process, generating a net forward flow of the neuronal cytoplasm (Hatten, 1993). Second, cytoskeletal elements are thought to underlie the two classes of neuron-glia appositions seen during migration - a specialized interstitial junction along the interface of the cell soma and glial fiber, and punctae adherentia along the length of the leading process. Along the interstitial junction, the intracellular space contains thin fibers that are contiguous with, or are transmembranous extensions of, submembranous elements that appear to attach to microtubules (Gregory et al., 1988). Moreover, antibody perturbation studies provide evidence that antibodies against the ncuron-glia ligand astrotactin significantly reduce the rate of neuronal migration, induce disorganization of cytoskeletal components, and cause withdrawal of the leading process (Fishell and Hatten, 1991). In particular, treatment of granule neurons with anti-astrotactin antibodies results in tangles of cytoskeletal elements in the area rostral to the nucleus (Fishell and Hatten, 1991). This result has suggested that the neuronal cytoskeleton interacts with neuron-glia receptor systems to produce movement of the cell soma.

To provide a detailed view of the motile behavior of the leading process, we labeled granule neurons, purified from early 
postnatal mouse cerebellum, with the fluorescent lipophilic dye, PKH-26 (Horan and Slezak, 1989; Gao et al., 1992). The labeled neurons were plated on unlabeled glial fibers and migration was visualized by time lapse fluorescence microscopy. This allowed us to view the motility of the leading process separately from the surface activity of the underlying glial fiber. During migration the leading process rapidly extended, projecting up to 40 $\mu \mathrm{m}$, and retracted, withdrawing towards the rostral portion of the cell soma. Lamellipodial and filopodial extension occurred along the entire length of the leading process. Treatment of migrating neurons with cytochalasin $\mathrm{B}$, a drug that disrupts actin filaments (Forscher and Smith, 1988; Letourneau et al., 1987), rapidly arrested neuronal migration, suggesting that actin subunit assembly functions in neuronal locomotion along the glial substrate. In contrast to the growth cone, where actin filaments and microtubules are separated into distinct peripheral and central domains, the leading process did not show the development of a distinct actin-rich domain at its tip.

\section{Materials and Methods}

Purification of cerebellar granule neurons and astroglial cells. Cell suspensions enriched in cerebellar granule neurons $(95 \%)$ and astroglia $(5 \%)$ were purified by Percoll gradient sedimentation from $\mathrm{C} 57 \mathrm{Bl} / 6 \mathrm{~J}$ mice on postnatal days 5 or 6 (Hatten, 1985). Cells were plated in serumsupplemented medium (BME plus $10 \%$ horse serum, $9 \mathrm{mg} / \mathrm{ml}$ glucose, $0.3 \mathrm{mg} / \mathrm{ml}$ glutamine, $50 \mathrm{U} / \mathrm{ml}$ penicillin, and $50 \mu \mathrm{g} / \mathrm{ml}$ streptomycin) as described (Edmondson and Hatten, 1987) on glass coverslip microculture wells pretreated with laminin (Collaborative Research, Lexington, $\mathrm{MA} ; 10 \mu \mathrm{g} / \mathrm{cm}^{2}$ in CMF.PBS at $4^{\circ} \mathrm{C}$ for $12-24 \mathrm{hr}$ ), and maintained at $35.5^{\circ} \mathrm{C}$ with $100 \%$ humidity and $5 \% \mathrm{CO}_{2}$.

Dye labeling of purified granule neurons. A purified ( $>99 \%$ ) population of immature granule cells was prepared as described by Gao et al. (Gao et al., 1991) and labeled with the fluorescent lipophilic dye PKH-26 (Gao et al., 1992). Labeled granule cells were then added to cultures of unlabeled cerebellar granule cells $(95 \%)$ and astroglia $(5 \%)$, which had been plated $24 \mathrm{hr}$ earlier to allow extension of the glial fiber system in the cultures.

Preparation of glass fibers. Glass fibers of a geometry and diameter similar to radial glial fibers $(0.5-2 \mu \mathrm{m}$ in width and up to $100 \mu \mathrm{m}$ in length) were prepared from Whatman glass fiber filters as described (Fishman and Hatten, 1993). In the present experiments, glass fibers were coated with polylysine (100 $\mu \mathrm{g} / \mathrm{ml} ; 2 \mathrm{hr}$ at room temperature) and then with laminin $\left(50 \mu \mathrm{g} / \mathrm{ml} ; 4 \mathrm{hr}\right.$ at $\left.4^{\circ} \mathrm{C}\right)$ prior to placement in glass coverslip microwells (see above) pretreated with polylysine $(100 \mu \mathrm{g} / \mathrm{ml})$. To provide trophic support for the purified granule cells, astroglial cells were plated on a coverslip, which was inverted as a "ceiling" over the microwell.

Migration of dye-labeled granule neurons on native cerebellar glial fibers. Migration of granule neurons along glial processes was monitored with time lapse video microscony. Cultures were washed twice with Leibovitz's L-15 medium (GIBCO) containing Redu-Ser II (Upstate Biotechnology), $10 \mathrm{~mm}$ HEPES, $0.3 \mathrm{mg} / \mathrm{ml}$ glutamine, $50 \mathrm{U} / \mathrm{ml}$ penicillin, $50 \mu \mathrm{g} / \mathrm{ml}$ streptomycin, and $9 \mathrm{mg} / \mathrm{ml}$ glucose. An $18 \mathrm{~mm}$ coverslip was mounted over the microwell (Edmondson and Hatten, 1987), and the sealed chamber was placed on the stage of a Zeiss Axiovert microscope. The specimen, objective, and condenser were heated to $33-35^{\circ} \mathrm{C}$ by a Zeiss TRZ 3700 heating stage. Images of granule cell migration were acquired with three optical systems. For video-enhanced contrast differential-interference contrast (VEC-DIC) microscopy, cells were mounted on a Zeiss Axiovert-35 inverted microscope equipped with differential interference contrast optics $(20 \times / 0.5,40 \times / 0.75,63 \times / 1.4$, or $100 \times / 1.3 \mathrm{NA}$ objectives). Images were acquired with a Hamamatsu C1965 video camera. A Uniblitz shutter and T132 shutter driver were controlled by the Image-1 system (Universal Imaging). Images were recorded with a Panasonic optical memory disk recorder every 3 min in the case of low magnification assays, and every 3-5 $\mathrm{min}$ in the case of high magnification assays.

Images of granule cells labeled with $\mathrm{PKH}-26$ were acquired with either confocal microscopy or with a light-intensified charged-coupled device (I-CCD). Confocal microscopy was performed using a Zeiss Axiovert microscope fitted with a Bio-Rad MRC 600 confocal scan head with
$568 \mathrm{~nm}$ illumination from a krypton-argon multiline laser. A Nomarski image was obtained by transmitting the laser light through an optic fiber cable. Alternatively, PKH-labeled cells were imaged using a Hamamatsu 2400-50/80 I-CCD camera head and controller. Epifluorescent excitation/emission was at $510 / 550 \mathrm{~nm}$. Three neutral density filters were added to reduce the excitation light level by $99 \%$. For time lapse recordings using the I-CCD, one image ( $100 \mathrm{msec}$ exposure) was acquired every $3-5 \mathrm{~min}$.

Disruption of cytoskeletal structures of migrating neurons with cytochalasin $B$ or nocodazole. To infuse agents that disrupt cytoskeletal elements, the cover of the microculture system was modified. Rather than sealing the microwell with a second \#1 coverslip, the petri dish was filled with glial-conditioned medium $(14 \mathrm{ml})$. The culture was sealed with a petri dish cover fitted with a "window" (obtained by drilling a hole $(14 \mathrm{~mm})$ in the top and sealing with a $\# 1$ coverslip). Additions of concentrated stocks of nocodazole or cytochalasin were made through a second hole $(6 \mathrm{~mm})$ in the plastic petri dish cover which was sealed with Parafilm before and after drug additions. For drug addition experiments, Nomarski images were acquired with a Zeiss Axiovert microscope fitted with a long working distance condenser.

Immunocytochemical procedures. Tubulin and actin were localized by a procedure modified from Wang et al. (1982). In brief, cells were washed once with calcium-free Hanks' balanced salt solution and once with cytoskeleton buffer (CD; Ilanks' BSS plus $2 \mathrm{~mm} \mathrm{MgCl}_{2}, 2 \mathrm{~mm}$ EGTA, 5 mм PIPES, pH 6.9). The cells were then treated for $1 \mathrm{~min}$ with $C B$ plus $0.25 \%(\mathrm{w} / \mathrm{v})$ glutaraldehyde, $0.5 \%(\mathrm{w} / \mathrm{v})$ Triton $\mathrm{X}-100$, rinsed in $\mathrm{CB}$, and then postfixed (1\% glutaraldehyde in $\mathrm{CB}, 10 \mathrm{~min})$. After further permeabilization in $0.5 \%$ Triton $X-100$ in CB $(10 \mathrm{~min})$, aldehyde autofluorescence was quenched with $1 \mathrm{mg} / \mathrm{ml} \mathrm{NaBH}_{4}$ in cytoskeleton buffer (three $10 \mathrm{~min}$ incubations). The cells were washed in $\mathrm{CB}$ and actin microfilaments were stained with rhodamine-phalloidin (Molecular Probes). For tubulin staining, cells were rinsed with antibody buffer (PBS plus 1\% Triton $X-100$ ) and stained sequentially with a mouse monoclonal antibody to $\beta$-tubulin (Amersham) and fluoresceinconjugated, goat anti-mouse and rabbit anti-goat, affinity-purified secondary antibodies (Cappel). In some experiments, granule neurons were stained for actin filaments and microtubules sequentially with BODIPY phalloidin (Molecular Probes; $558 \mathrm{~nm}$ excitation maximum, $568 \mathrm{~nm}$ emission maximum), mouse monoclonal antibody to $\beta$-tubulin (Amersham), and affinity-purified, fluorescein-conjugated, goat anti-mouse antiserum. Fluorescently stained cultures were scanned for neurons having the elongated, bipolar shape typical of migrating neurons (Edmondson and Hatten, 1987).

\section{Results}

\section{The leading process is highly dynamic}

Previous views of glial-guided neuronal migration in vitro using VEC-DIC microscopy showed high-resolution details of migration of the neuronal soma and the proximal portion of the leading process (Edmondson and Hatten, 1987; Fishell and Hatten, 1991). Although VEC-DIC microscopy allowed visualization of the leading process in real time, the small diameter of the process (less than $1 \mu \mathrm{m}$ ) and the motility of the surface of the underlying glial fiber made it difficult to image leading process motility. To provide a detailed view of the movements of the leading process, in isolation from the surface activity of the underlying glial fiber, freshly purified granule neurons were labeled with the fluorescent lipophilic membrane dye, PKH-26 (Horan and Slezak, 1989; Gao et al., 1991, 1992; Gao and Hatten, 1993) and were added to neuron-glial migration cultures that had been plated earlier to allow extension of the glial fiber system. PKH-labeled neurons attached to glial fibers and appeared indistinguishable from unlabeled neurons by differentialinterference contrast microscopy, adopting the elongated bipolar shape characteristic of migrating neurons (Edmondson and Hatten, 1987; Gregory et al., 1988; Fishell and Hatten, 1991). Using PKH-26 we were able to image the entire extent of the leading process moving through a complex culture environment of glial processes and neurites. 

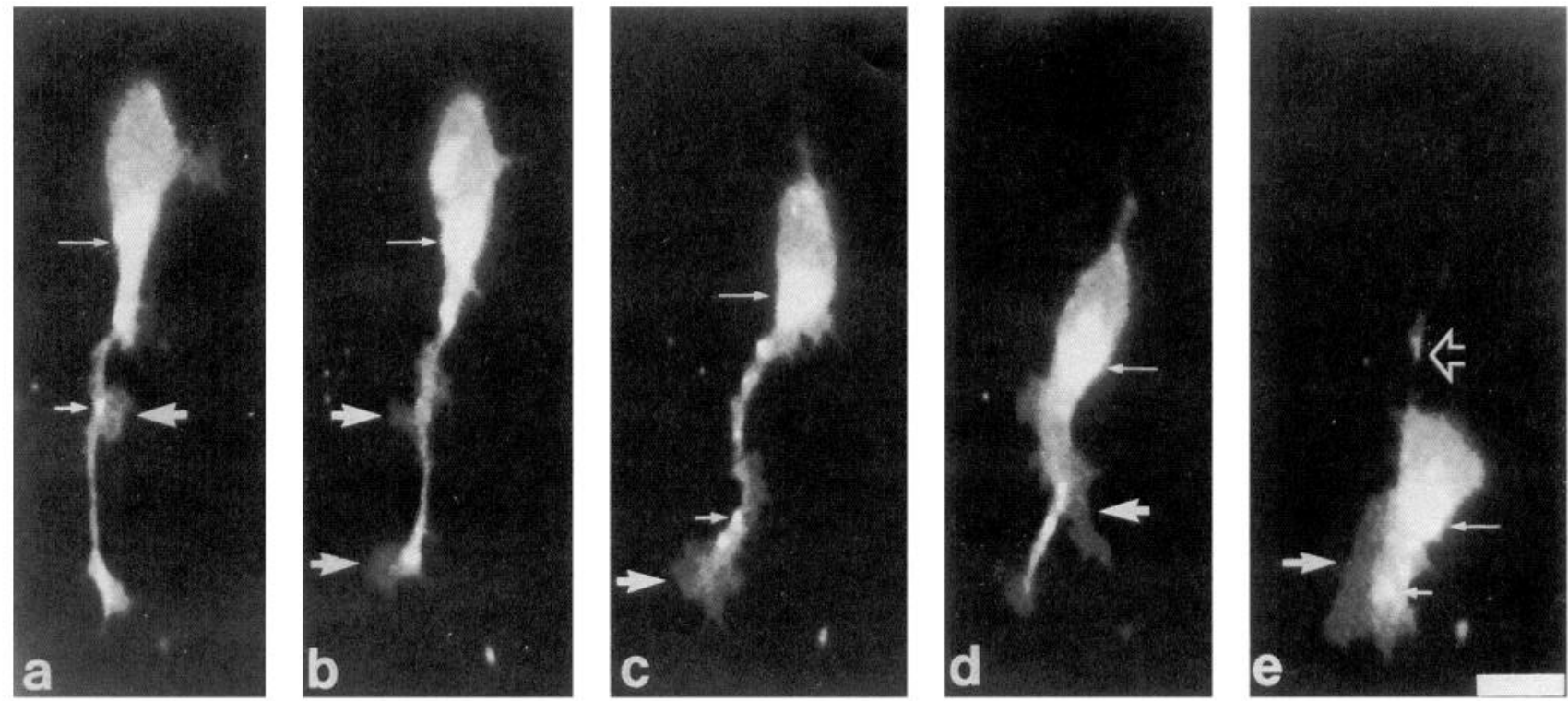

Figure 1. PKH-26 labeling of migrating granule neurons. Freshly purified granule neurons were labeled with the fluorescent lipophilic membrane dye, PKH-26, and added to neuron-glial migration cultures. The labeled neurons attached to extended glial processes in the cultures and were examined by time lapse fluorescence microscopy with an I-CCD camera. Highly motile lamellipodia (large arrow in $a-e$ ) were present along the length of the leading process. A juxtanuclear area of fluorescently labeled organelles (long, thin arrows in $a-e$ ), which apparently took up the dye from the plasma membrane by endocytosis, was located just rostral to the caudally oriented nucleus. Fluorescently labeled vesicles (short arrows in $a, c, e$ ) could be seen streaming down the leading process during migration. A short process was observed trailing from the migrating cell (open arrowhead). Time points (min): $a, 0 ; b, 10 ; c, 33 ; d, 67 ; e, 139$. Scale bar, $5 \mu \mathrm{m}$.

A novel finding revealed with $\mathrm{PKH}-26$ labeling was that migrating neurons in vitro had highly elongated leading processes (10-40 $\mu \mathrm{m}$ in length) extending along the underlying glial fiber (see Figs. 1, $5 a-c$ ). During migration, the leading process extended away from, and then retracted towards the cell soma in an accordion-like fashion over a period of minutes or hours (see Figs. 1, $5 a-c)$. The average length of the leading process, as determined from fluorescence micrographs, was $30.3 \pm 6.3 \mu \mathrm{m}$ (mean \pm SEM); extensions or retractions of the leading process during migration of the cell soma averaged $8.9 \pm 2.1 \mu \mathrm{m}$. In some instances, the leading process retracted into the cell soma and then reextended in the direction of cell migration (not shown). Alternatively, as the neuron reversed the direction of migration, the leading process withdrew into the soma and reextended along the glial fiber in the direction opposite to the previous direction of cell migration. $\mathrm{PKH}-26$ labeling revealed numerous broad lamellipodial extensions along the entire length of the leading process (see Figs. 1, $5 a-c$ ). Rapid extension and retraction of lamellipodia was common, with occasional fine filopodia evident. The numerous lamellipodial extensions along the leading process gave it a ruffled appearance (see Figs. $1,5 a-c$ ). Thus, during migration the granule neuron extends and retracts a thickened, highly dynamic leading process with lamellipodial and filopodial extensions all along its length.

\section{Polarity of the migrating neuron}

As the neuron moved along the glial guide, fluorescently labeled internal structures were visible, owing to an apparent uptake of PKH-26 from the surface membrane. Dense fluorescence was seen in the cell soma just rostral to the nucleus in the direction of migration; this staining probably represented endosomes, lysosomes, or the Golgi (see Figs. 1, $5 a-c$ ). This view was confirmed by staining for internal membranes with the dicarbocyanine dye, $\mathrm{DiOC}_{6}(3)$ (Terasaki, 1989), which also showed an area of dense staining of membranous organelles just rostral to the nucleus (Fig. 2b). This juxtanuclear area has been reported in ultrastructural studies to contain microtubule-associated organelles such as ER, mitochondria, the Golgi apparatus, and basal bodies (Gregory et al., 1988).

The nucleus remained in the posterior portion of the cell soma during neuronal migration (see Figs. 1, 2, 4, 5). The rostral end of the nucleus frequently showed an indentation, or notch, in the direction of migration. This notch was seen in both time lapse observations of PKH-labeled neurons (not shown) and by examination of fixed neurons stained with $\mathrm{DiOC}_{6}(3)$ (Fig. $2 b$ ), confirming previous video and ultrastructural studies (Edmondson and Hatten, 1987; Gregory et al., 1988). Thus, the migrating granule neuron is highly polarized in the direction of migration, positioning the nucleus in the posterior aspect of the cell and localizing membranous organelles in a juxtanuclear area just rostral to nucleus.

\section{Organization of microtubules in migrating neurons}

Evidence for a role for microtubules in neuronal migration has come from electron microscopic studies revealing an association of submembranous microtubules with the interstitial junction, the site of adhesion between the neuronal cell soma and the glial process (Gregory et al., 1988). To view the organization of microtubules in the cell soma and the leading process of migrating cells, we immunostained migrating neurons with a monoclonal antibody against $\beta$-tubulin. By immunostaining, microtubules formed a "cage-like" web of filaments circumscribing the nucleus in the caudal aspect of the cell (Fig. 3a). Rostral to the nucleus, a dense array of longitudinally oriented microtubules extended into the leading process (Fig. $3 a$; cf. Gregory et al., 1988).

Although optical sectioning of immunolabeled microtubules by confocal microscopy delineated the cage of microtubules 

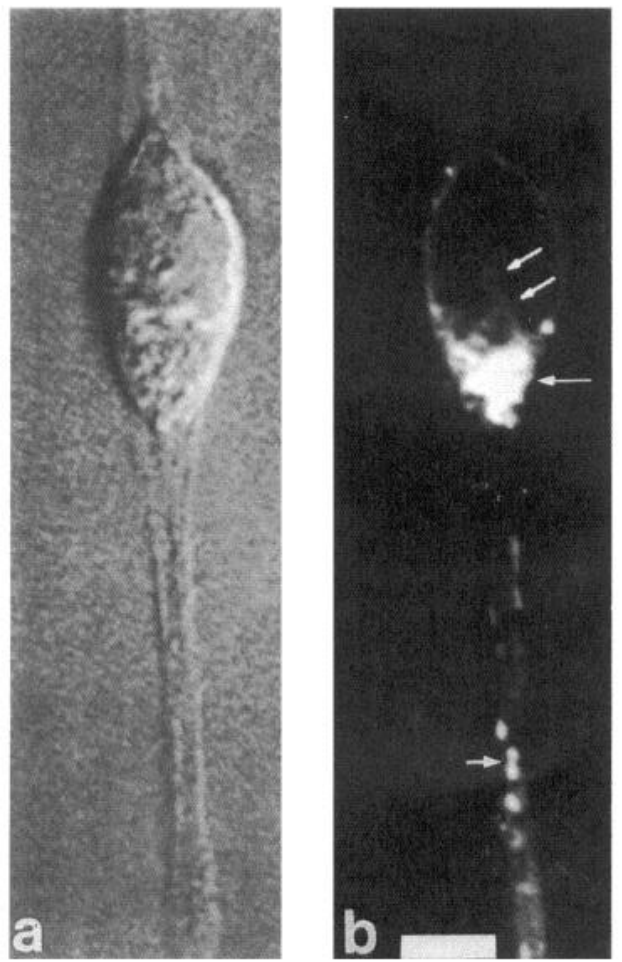

Figure 2. DiOC $_{6}(3)$ staining of intracellular membranes in migrating granule neurons. The dicarbocyanine dye $\mathrm{DiOC}_{6}(3)$ was used to stain mitochondria, endoplasmic reticulum, and other internal membranes in glutaraldehyde-fixed neuron-glial migration cultures, which were then examined by confocal microscopy. $a$, Nomarski micrograph of granule neuron migrating on a glial fiber. The direction of migration is towards the bottom of the panel. $b$, Fluorescence confocal image corresponding to the cell in $a$. A bright juxtanuclear area of fluorescently labeled internal membranes (single long arrow) was observed rostral to the nucleus in the direction of migration. A distinctive notch in the nucleus (double arrows in $b$ ) pointed in the direction of migration. Fluorescently labeled vesicles (short arrow) could also be seen in the leading process. Scale bar, $4 \mu \mathrm{m}$.

surrounding the nucleus, the organization of microtubules in $z$-planes near the interstitial junction and in regions of the leading process that apposed the glial fiber was difficult to assess. To view neuronal microtubules in isolation from glial microtubules, we immunostained granule cells migrating along laminin-coated glass fibers (Fishman and Hatten, 1993). By video microscopy, the dynamics and general mode of movement of granule cell migration along glass fibers closely resembles neurons migrating along glial processes (Fishman and Hatten, 1993). Immunocytochemical localization of microtubules confirmed the perinuclear, cage-like distribution of microtubules seen in cells migrating on native astroglial fibers (Fig. $4 b, d$ ). Within the leading processes, a dense array of longitudinally oriented microtubules could be seen spiraling around the shaft of the glass fiber (Fig. $4 c, d$ ).

\section{Organization of actin filaments in migrating neurons}

The regulation of assembly of actin subunits plays a critical role in generating fibroblast locomotion (Abercrombie et al., 1970; Bray and White, 1988; Stossel, 1993) and in guiding the directionality of the growth cone (Letourneau and Ressler, 1983; Marsh and Letourneau, 1984; Letourneau et al., 1987; Forscher and Smith, 1988; Mitchison and Kirschner, 1988; Smith, 1988; Bridgman and Dailey, 1989). To examine the organization of

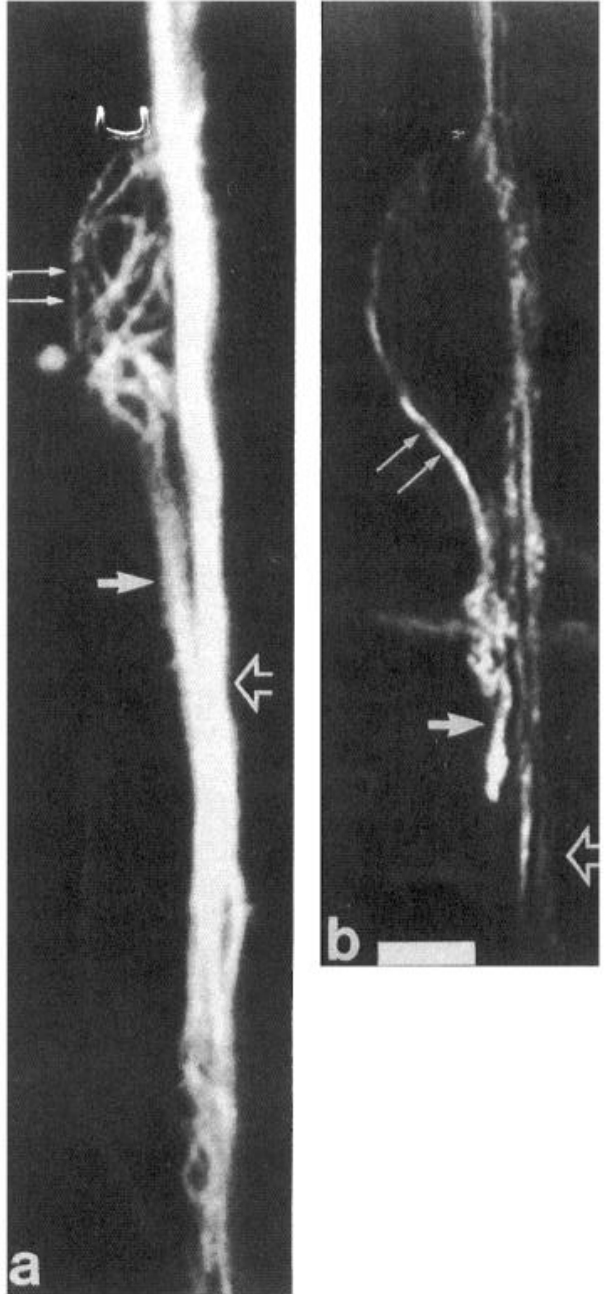

Figure 3. Distribution of microtubules and actin filaments in migrating granule neurons. Neuron-glial migration cultures were fixed and stained by indirect immunofluorescence with $\beta$-tubulin antibody $(a)$ or, alternatively, with rhodamine-labeled phalloidin to stain filamentous actin (b). Cultures were examined by confocal microscopy. The direction of migration is towards the bottom of the figure. $a$, Examination of neurons with migration profiles revealed a cagelike network of microtubules in the neuronal cell body (double arrows) and longitudinally arrayed microtubules extending into the leading process (single large arrow). The microtubules in the underlying glial fiber are indicated by the open arrowhead. $b$, Filamentous actin was particularly concentrated in the leading process (large arrow) and in a subcortical rim in the cell body (double arrows). Actin filament staining in the underlying glial fiber is indicated by the open arrowhead. Scale bar, $4 \mu \mathrm{m}$.

actin filaments in migrating granule neurons, we visualized filamentous actin by rhodamine-phalloidin staining. Within the cell soma, actin staining was concentrated in a thin, subcortical rim underneath the plasma membrane (Fig. $3 b$ ). Filamentous actin was also seen in lamellipodial and filopodial extensions of the leading process (Fig. $3 b$ ). To discriminate actin networks in the leading process from those in the underlying glial fiber, we imaged the actin filaments of granule cells migrating on glass fibers. The organization of actin filaments in granule cells undergoing migration along glass fibers closely resembled that seen for cells migrating on native glial fibers. By phalloidin staining, a thin rim of cortical actin was seen under the cell soma of the migrating cell, with heavy staining observed along the length of the migratory process (see Fig. $8 b$ ). 

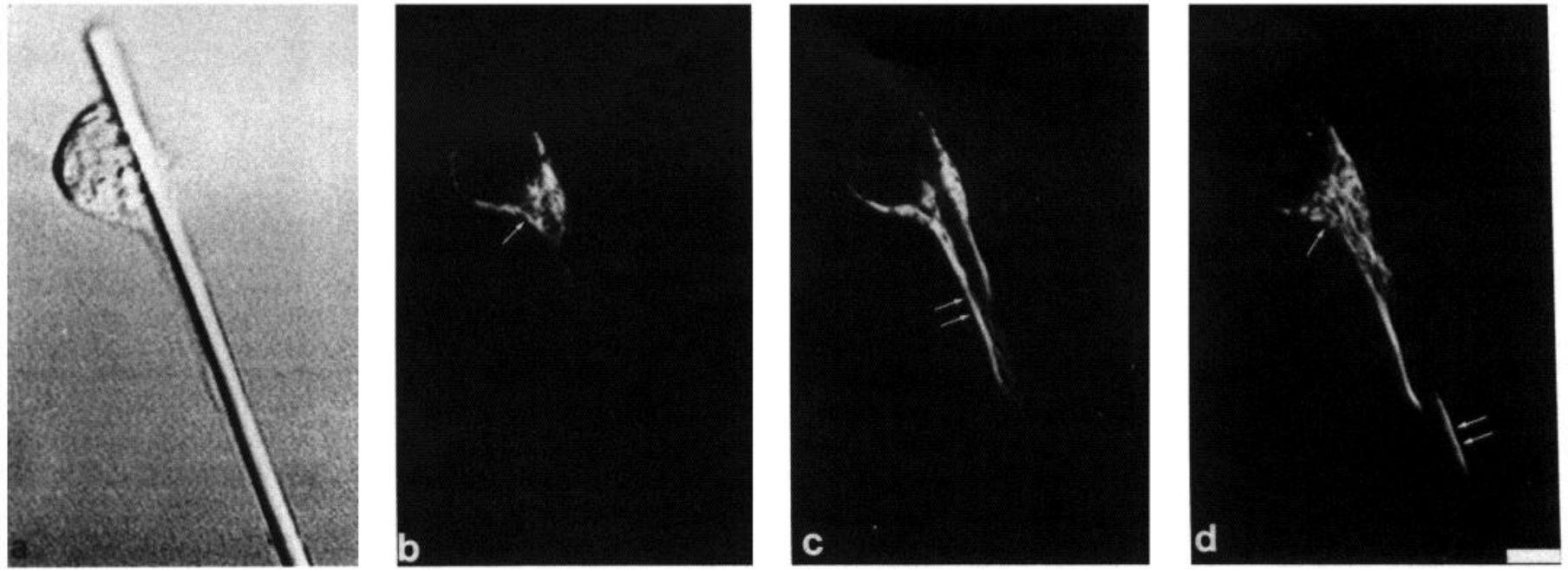

Figure 4. Distribution of microtubules in granule neurons migrating on laminin-coated glass fibers. Granule neurons migrating on laminin-coated glass fibers were fixed, stained by indirect immunofluorescence with a monoclonal antibody to $\beta$-tubulin, and examined by confocal microscopy. $a$, Nomarski micrograph of migrating granule neuron. The direction of migration is towards the bottom of the panel. $b-d$, Confocal fluorescence images corresponding to same cell as in $a$. Optical sections started $1.5 \mu \mathrm{m}(b)$ from the top of the cell body and were taken towards $(d)$ the glass coverslip; optical sections are $1.0 \mu \mathrm{m}$ apart. Note the cage-like network of microtubules in the cell body (single arrow in $b$ and $d$ ). Spiraling microtubules could be seen coursing down the leading process (double arrow in $c$ and $d$ ). Scale bar, $4 \mu \mathrm{m}$.

\section{Disruption of the organization of actin filaments in migrating granule cells}

To examine the contribution of actin filaments to the movement of neurons along the glial fiber, migrating cells were treated with cytochalasin B, an agent that disrupts actin filaments (Marsh and Letourneau, 1984; Letourneau et al., 1987; Forscher and Smith, 1988). A computer-assisted VEC-DIC microscopy assay was used to track the behavior of migrating granule neurons before and after drug treatment (Fishell and Hatten, 1991). A marked reduction in the movement of migrating neurons along glial processes occurred after treatment with cytochalasin B. Migration rates in untreated cells averaged $24.1 \pm 8.6 \mu \mathrm{m} / \mathrm{hr}$; after a $2 \mathrm{hr}$ treatment with cytochalasin B, migration rates averaged $3.3 \pm 1.7 \mu \mathrm{m} / \mathrm{hr}(10 \mu \mathrm{M}$ cytochalasin B) or $6.9 \pm 3.4$ $\mu \mathrm{m} / \mathrm{hr}$ (20 $\mu \mathrm{M}$ cytochalasin B). By VEC-DIC microscopy, the cell soma of cytochalasin-treated neurons assumed a rounded profile characteristic of stationary neurons (Gregory et al., 1988). Notably, treated cells remained attached to the glial processes, suggesting that disruption of actin filaments was not sufficient to disrupt neuron-glial adhesion.

The effect of cytochalasin B treatment on the motility of the leading process was examined in $\mathrm{PKH}-26$ labeled neurons using time-lapse confocal microscopy. Treatment with cytochalasin $\mathrm{B}$ appeared to freeze the broad lamellipodia enwrapping the glial fiber within a period of a few minutes (Fig. $5 d, e$ ). Over a period of 20-30 $\mathrm{min}$, the leading process appeared to collapse into a flattened expanse of membrane, and motility of the cell soma halted (Fig. 5d,e). Although lamellipodial and filopodial activity was rapidly reduced, movement of intracellular vesicles was seen in PKH-26 labeled cells after the addition of cytochalasin B, suggesting that organelle and vesicle transport in the cell soma was not affected, at least in the short term (not shown). These results suggest that actin filaments are necessary both for the motility of the leading process and for the movement of the neuronal cell soma.

To assess the role of microtubules in neuronal migration, the cells were treated with nocodazole, a drug that disrupts microtubules (Bamburg et al., 1986; Joshi et al., 1986). In contrast to results with cytochalasin $\mathrm{B}$, treatment of neuronal-glial cultures with either 10 or $20 \mu \mathrm{M}$ nocodazole had more general effects, inducing a collapse of both glial processes and neurites. The neuronal cell bodies were pulled towards the glial cell bodies as the glial processes retracted, apparently due to the rapid collapse of microtubules within the glial process (not shown). This made it difficult to determine neuronal migration rates after drug treatment and quantitation was not performed.

\section{Granule cell axon extension: comparison with cell migration}

To compare the basic mechanisms underlying the extension of the granule cell neurite with the locomotion of the cell soma along the glial fiber, we first examined the motility of granule cell neurites. In contrast to the leading process, the shaft of the granule cell neurite was smooth (Fig. $6 a-c$ ), ending in a growth cone with numerous filopodia and lamellipodia (Fig. $6 a$ ). Indeed, the extension of filopodia and lamellipodia in the growing neurite was generally confined to the growth cone (cf. Harrison, 1910; Ramon y Cajal, 1911; Weiss, 1941; Bray and Hollenbeck, 1988; Bray and White, 1988). By time lapse microscopy, as the growth cone advanced, the neuritic shaft remained stable and did not undergo cyclic extension and retraction towards the cell soma (not shown). Thus, a key feature, evident in time lapse recordings of PKH-labeled granule cell neurites, was growth cone locomotion resulting in net growth of the axon. Granule cell neurites were observed to project up to several hundred micrometers along the culture surface over an observation period of several days in vitro.

Localization of $\beta$-tubulin and actin filaments within granule neuron growth cones revealed a dense microtubular system in the shaft of the granule cell neurite, with two cytoplasmic domains evident within the growth cone region (cf. Forscher and Smith, 1988; Mitchison and Kirschner, 1988; Bridgman and Dailey, 1989; Rivas et al., 1992). Whereas the central domain of the growth cone was rich in microtubules (Fig. $7 b, c)$, actin 

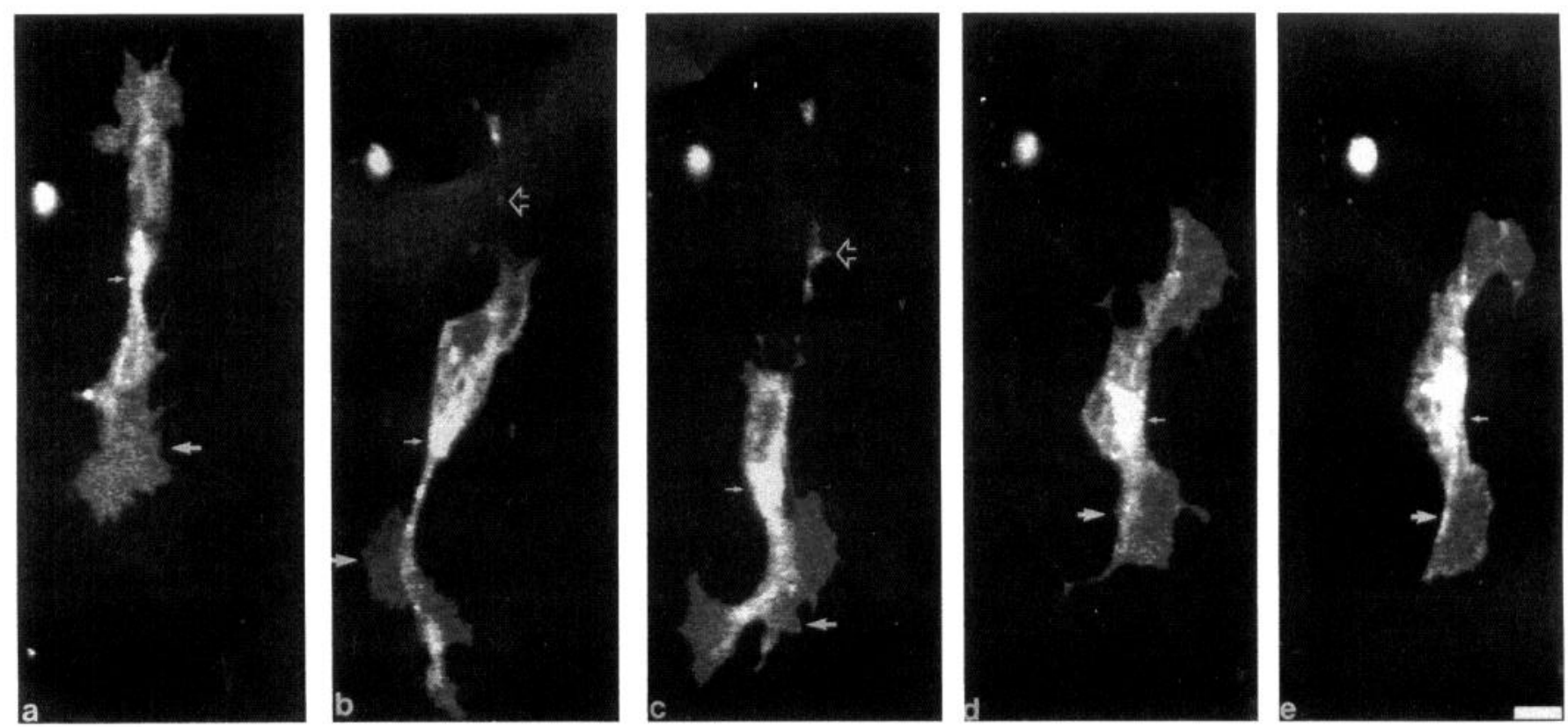

Figure 5. Effect of cytochalasin B on granule neuron migration. PKH-26 labeled granule neurons were observed in neuron-glial migration cultures by time lapse confocal microscopy before $(a-c)$ and after addition $(d, e)$ of $10 \mu \mathrm{M}$ cytochalasin B. $a-c$, In untreated cells, PKH-26 was particularly concentrated in the juxtanuclear area (single small arrows) rostral to the nucleus. Large, highly motile lamellipodia (large arrow) were present in the leading process. A short process trailed the migrating cell (open arrowhead in $b$ and $c$ ). $d$ and $e$, Addition of cytochalasin B to the culture medium within minutes caused a loss of motility of lamellipodia in the leading process (large arrow). The time point in $d$ is 9 min after the addition of cytochalasin $\mathrm{B} ; e, 45 \mathrm{~min}$ after the addition of the drug. The juxtanuclear area (small arrows) of fluorescently labeled organelles was no longer polarized in the direction of migration after the addition of cytochalasin B, although movement of vesicles and fluorescently labeled membranous tubules could still be observed. Time points (hours, minutes): $a, 00: 35 ; b, 3: 42 ; c, 4: 01 ; d, 4: 16 ; e, 4: 52$. Scale bar, $6 \mu \mathrm{m}$.

filament labeling was intense in the periphery of the growth cone (Fig. $7 a, c$ ). In contrast to growth cones, both microtubule and actin filament staining was evident along the length of the leading process (Fig. 8), with double-labeling experiments demonstrating that a distinct actin-rich domain was not evident at the tip of the leading process (Fig. $8 b, c$ ).

\section{Discussion}

In the present experiments, visualization of cerebellar granule neurons with the fluorescent lipophilic dye PHK-26 revealed that the leading process undergoes an accordion-like extension and retraction during neuronal migration along the glial guide. While it is clear that there is overlap in some aspects of the motility and cytoskeletal organization of the growth cone and leading process, the leading process has several distinctive features. Perhaps the most dramatic is the rapid extension and retraction of the leading process during cell locomotion. This differed from granule cell axon extension because the motility of the growth cone results, over time, in net lengthening of the axon. Indeed, granule cell axons extend over distances of several
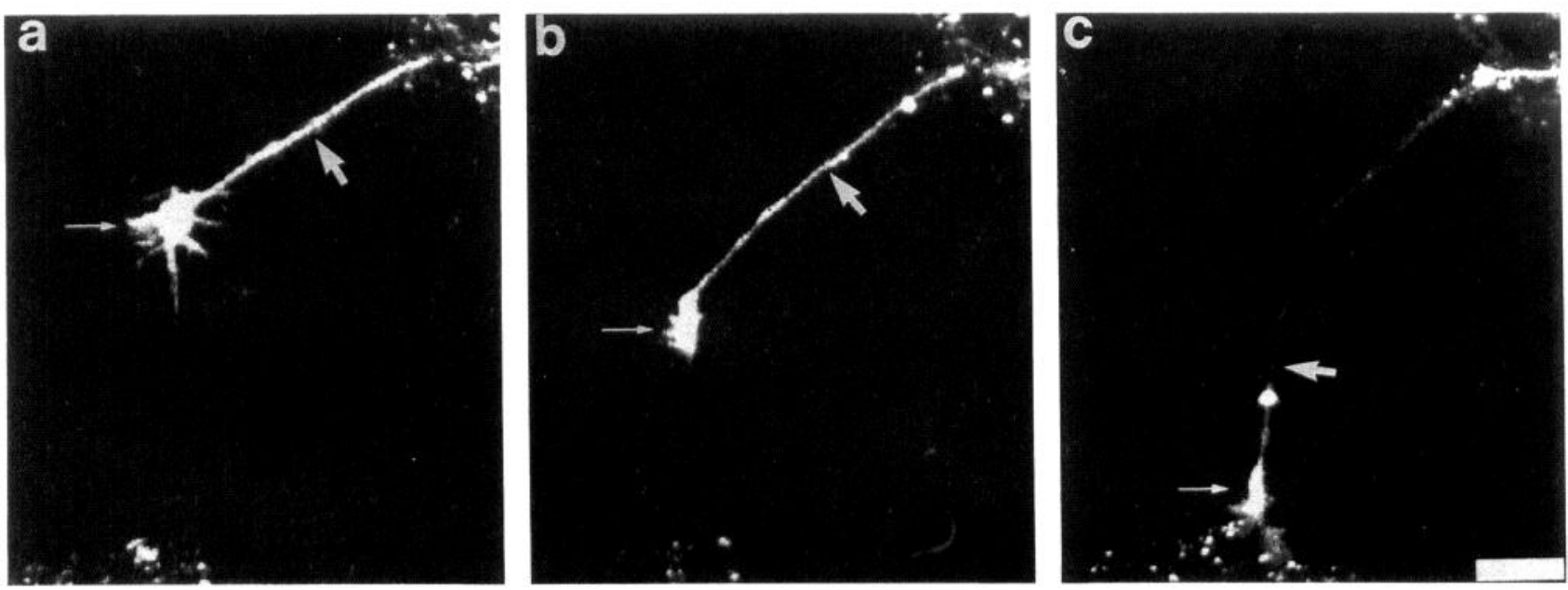

Figure 6. Extension of granule cell neurites. A single neurite from a PKH-26 labeled granule neuron was observed by time lapse fluorescence confocal microscopy extending on the laminin-coated glass substrate of a neuron-glial migration culture at three different time points $(a-c)$. A highly motile growth cone (long arrow in $a-c$ ) is seen at the ending of a long, thin neurite (large arrow in $a-c$ ). Motile activity of lamellipodia and filopodia was confined to the growth cone. Time points (min): $a, 0 ; b, 21 ; c, 54$. Scale bar, $4 \mu \mathrm{m}$. 

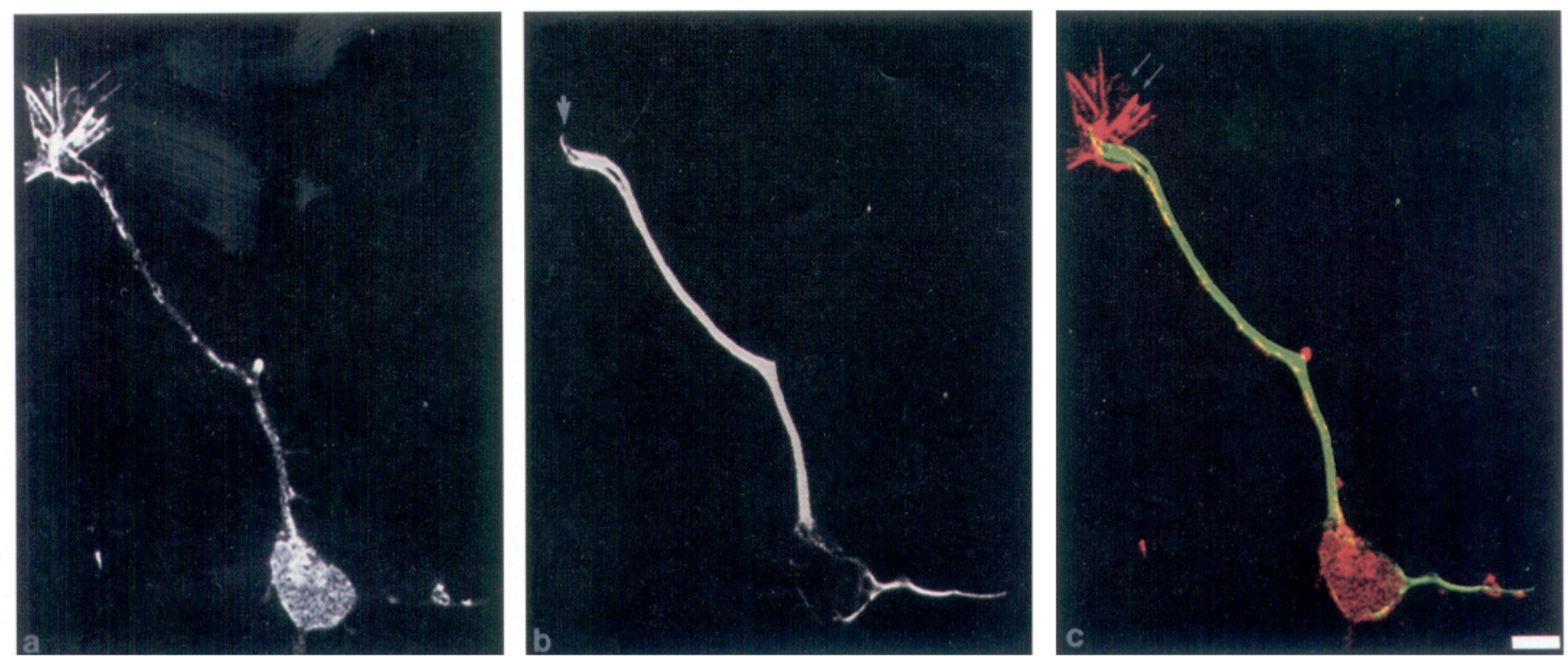

Figure 7. Distribution of microtubules and actin filaments in granule cell neurites. Granule neurons extending neurites on a polylysine substrate were fixed and double stained for $\beta$-tubulin using indirect immunofluorescence and for actin filaments using BODIPY phalloidin. The same cell is shown in $(a-c)$. Well-spread growth cones were observed on polylysine, with a heavy concentration of actin filaments in the peripheral lamellipodium (double arrows in $a$ ). Longitudinally oriented microtubules were observed in the neurites; these microtubules ended in the central domain of the growth cone (arrow in $b$ ). $c$, Digital merge of $a$ and $b$ showing distinct actin-rich peripheral (double arrows) and microtubule-rich central domains. Red fluorescence indicates actin, green fluorescence indicates tubulin. Scale bar, $7 \mu \mathrm{m}$.

hundred micrometers both in vitro and in vivo (Ramon y Cajal, 1911; Gao et al., 1991, 1992; Gao and Hatten, 1993). One clear difference in the cytoskeletal organization of the leading process is the absence of a distinct actin-rich domain at its tip. We propose that these differences in cytoskeletal organization and motility reflect initial steps in the development of granule cell polarity.

\section{Cytoskeletal organization of the migratory process}

A network of subcortical actin is thought to provide mechanical support to the surface of the cell, enabling the cell to undergo shape changes associated with locomotion. Since receptors for several classes of cell adhesion molecules bind actin filaments within the subcortical network, this network and the overlying surface membrane are often considered to be a single functional unit (Bray and White, 1988; Luna, 1991; Luna and Hitt, 1992). In the present experiments, the subcortical actin filaments observed in the neuronal soma may function in the inchwormlike extension and contraction of the soma characteristic of CNS migration along astroglial fibers (Hatten, 1990). The dense concentration of actin filaments seen in the leading process of cells undergoing migration is likely to function in the extension and retraction of lamellipodia and filopodia along the leading process. The arrest of cell locomotion observed after cytochalasin B treatment suggests that the assembly of actin subunits provides an important mechanism for cell migration.

In addition to actin-based mechanisms, it is likely that the microtubules of migrating neurons are specialized for locomotion of the cell soma. Several roles for microtubules in CNS cell migration are suggested by the current experiments. First, the accordion-like extension and retraction of the leading process along the glial guide suggests that the microtubules of the leading process are highly unstable, raising the possibility that assembly and disassembly of microtubules provides a net forward force for movement. Second, the cage-like web of microtubules seen in the cell soma may function to maintain caudal positioning of the nucleus as the rostral aspect of the cell extends. Finally, the array of longitudinal microtubules in the leading process may serve to orient the directionality of movement by providing a substrate for the directed flow of membranous organelles seen in migrating cells (Edmondson and Hatten, 1987).

\section{Comparison of cell migration with axon extension}

In the present study, several differences in the motility and cytoskeletal organization of granule cell neurites and the migratory leading process were evident. First, while the surface of the extending neuritic shaft was relatively quiescent (cf. Bray et al., 1978; Joshi et al., 1986), with filopodial and lamellipodial extensions confined primarily to the growth cone region, the entire length of the migratory process was "ruffled" with membranous extensions. Moreover, the leading process underwent rapid extension and retraction as the cell moved along the glial guide; in contrast, forward movement of the growth cone led over time to net extension of the neurite. The cyclic extension and retraction of the leading process during cell locomotion suggests that the microtubules of the leading process may be less stable than that of extending neurites (cf. Mitchison and Kirschner, 1988; Bulinski and Gundersen, 1991). Finally, whereas the growing tip of the granule cell neurite has a central region rich in microtubules and a peripheral region rich in actin filaments, the leading process did not have a distinct actin-rich domain.

\section{Development of cell polarity in the migrating neuron}

Migrating neurons are highly polarized in the direction of migration, with the nucleus positioned in the caudal aspect of the soma and microtubule-associated organelles, such as the ER, Golgi, and centrioles concentrated just rostral to the nucleus 

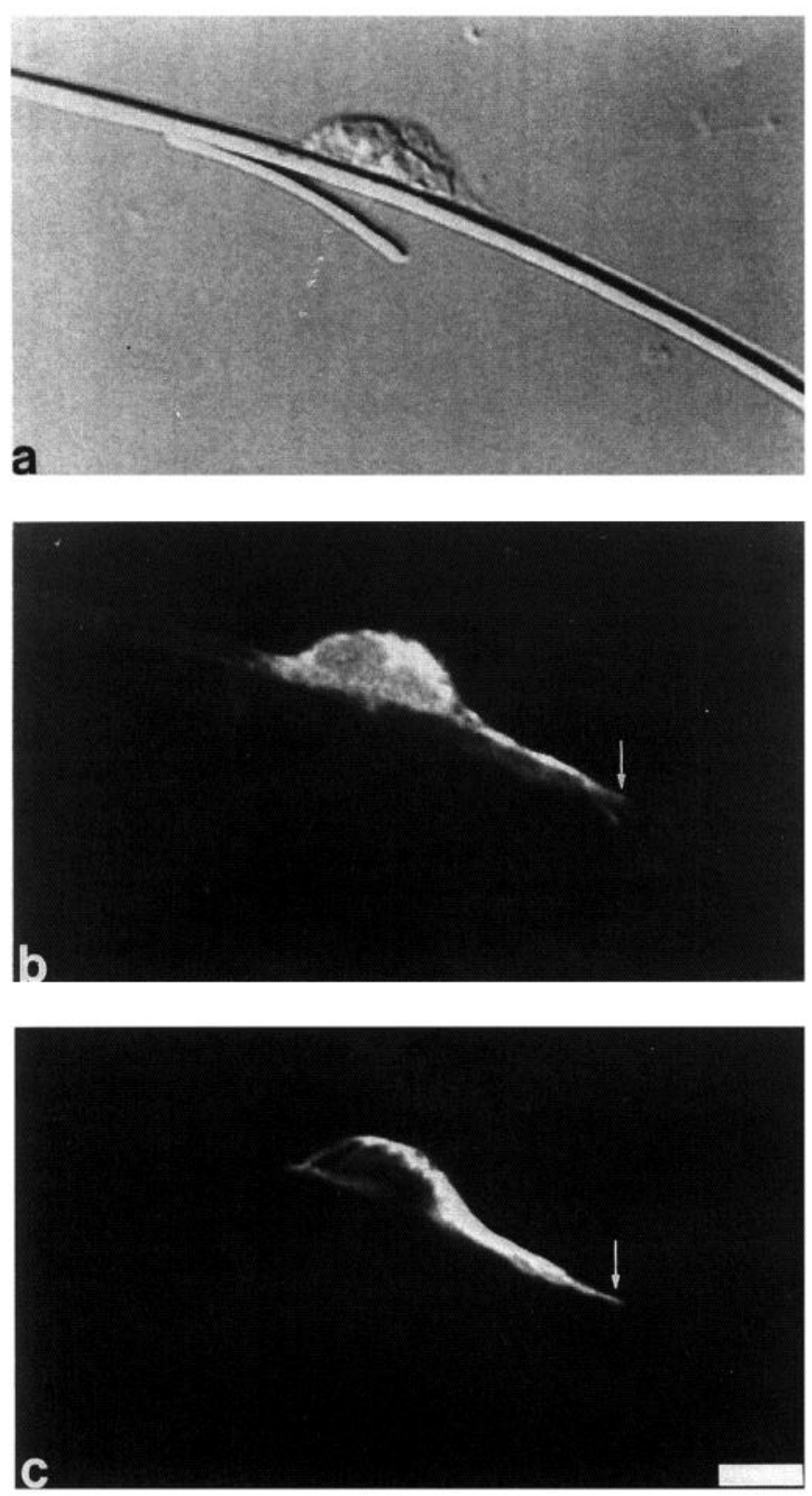

Figure 8. Distribution of microtubules and actin filaments in granule neurons migrating on laminin-coated glass fibers. Granule neurons migrating on polylysine laminin-coated glass fibers were fixed and double stained for $\beta$-tubulin by indirect immunofluorescence and for actin filaments with BODIPY phalloidin. The same cell is shown in $a-c$. The micrograph was taken from the same culture shown in Figure 7; the glass coverslip substrate is polylysine. $a$, Nomarski image of granule neuron with migration profile on glass fiber. $b$, Actin filament staining. $c$, Tubulin staining. Actin filament and microtubule distributions appeared to overlap extensively in the leading process (arrows in $b$ and c). Scale bar, $7 \mu \mathrm{m}$.

(Gregory et al., 1988). The presence of ribosomes and Golgi elements in the leading process (Gregory et al., 1988) gives it a dendritic, rather than axonal character (cf. Bridgman and Dailey, 1989; Craig et al., 1992; Rodriguez-Boulan and Powell, 1992). Observations of the leading process of migrating neurons led Ramon y Cajal to suggest that the leading process eventually transforms into the dendrites seen in postmigratory neurons (Ramon y Cajal, 1911).
Granule cell axonal extension in vivo is segregated both spatially and temporally from cell body migration and subsequent dendrite formation (Ramon y Cajal, 1911; Gao and Hatten, 1993). This spatiotemporal segregation is reflected both by differential gene expression at the various stages of granule cell development (Kuhar et al., 1993) and by differential protein distributions in the membrane domains of the developing neuron. A number of adhesive glycoproteins of the Ig superfamily (reviewed in Faivre-Sarrailh and Rougon, 1993), including L1 (Pershon and Schachner, 1987) and the glycosylphosphatidylinositol-linked molecules F3/F11 (Faivre-Sarrailh et al., 1992) and TAG-1 (Furley et al., 1990; Yamamoto et al., 1986, 1990) are localized only to the parallel fiber axons, not to the migratory or postmigratory granule cell bodies, leading processes, or dendrites. TAG-1 is also localized exclusively to the long, thin parallel fiber axon-like neurites we have observed in vitro $(\mathrm{S} . \mathrm{K}$. Powell, R. J. Rivas, E. Rodriguez-Boulan, and M. E. Hatten, unpublished observations).

The distinctive features of cytoskeletal organization and motility in the leading process are likely to subserve different protein expression patterns and functions from those of the growth cone. Thus, the development of distinct differences between the leading process and growth cone reflect the overall program of granule cell development, where changing patterns of gene expression mark the spatially and temporally discrete steps of axon extension, migration, and dendrite formation (Kuhar et al., 1993). In vivo, as visualized by implantation of $\mathrm{PKH}$-labeled granule neurons back into cerebellar cortex, this spatiotemporal segregation is a striking feature of granule cell identity (Gao and Hatten, 1993, 1994; Rivas and Hatten, unpublished observations), with implanted neurons developing leading process and axonal morphologies remarkably similar to those we have observed in the present experiments. Thus, the in vitro systems offer the opportunity to dissect the molecular events controlling targeting of proteins to distinct cellular locations in the granule neuron and the intracellular signaling events that control this specialized form of cytoskeletal organization.

\section{References}

Abercrombie M (1980) The crawling movement of metazoan cells. Proc R Soc Lond [Biol] 207:129-147.

Abercrombie M, Heaysman JEM, Pegrum SM (1970) The locomotion of fibroblasts in culture I. Movements of the leading edge. Exp Cell Res 59:393-398.

Bamburg JR, Bray D, Chapman K (1986) Assembly of microtubules at the tip of growing axons. Nature 321:788-790.

Bray D, Hollenbeck PJ (1988) Growth cone motility and guidance. Annu Rev Cell Biol 4:43-61.

Bray D, White JG (1988) Cortical flow in animal cells. Science 239: 883-888.

Bray D, Thomas C, Shaw G (1978) Growth cone formation in cultures of sensory neurons. Proc Natl Acad Sci USA 75:5226-5229.

Bridgman PC, Dailey ME (1989) The organization of myosin and actin in rapid frozen nerve growth cones. J Cell Biol 108:95-109.

Bulinski JC, Gundersen GC (1991) Stabilization and post-translational modification of microtubules during cellular morphogenesis. Bioessays 13:285-293.

Craig AM, Jareb M, Banker G (1992) Neuronal polarity. Curr Opinion Neurobiol 2:602-606.

Dunn GA, Heath JP (1976) A new hypothesis of contact guidance in tissue cells. Exp Cell Res 101:1-14.

Edmondson JC, Hatten ME (1987) Glial-guided granule neuron migration in vitro: a high-resolution time-lapse video microscopic study. J Neurosci 7:1928-1934.

Edmondson JC, Liem RKH, Kuster JE, Hatten ME (1988) Astrotactin, a novel cell surface antigen that mediates neuron-glia interactions in cerebellar microcultures. J Cell Biol 106:505-517. 
Faivre-Sarrailh C, Rougon G (1993) Are the glypiated adhesion molecules preferentially targeted to the axonal compartment? Mol Neurobiol 7:49-60.

Faivre-Sarrailh C, Gennarini G, Goridis C, Rougon G (1992) F3/F11 cell surface molecule expression in the developing mouse cerebellum is polarized at synaptic sites and within granule cells. J Neurosci 12: 257-267.

Fishell G, Hatten ME (1991) Astrotactin provides a receptor system for CNS neuronal migration. Development 113:755-765.

Fishman R, Hatten ME (1993) Multiple receptor systems promote CNS neuronal migration. J Neurosci 13:3485-3495.

Forscher P, Smith S (1988) Actions of cytochalasins on the organization of actin filaments and microtubules in a neuronal growth cone. J Cell Biol 107:1505-1516.

Furley AJ, Morton SB, Manalo D, Karagogeos D, Dodd J, Jessell TM (1990) The axonal glycoprotein TAG-1 is an immunoglobulin superfamily member with neurite outgrowth-promoting activity. Cell 61:157-170.

Gao WQ, Hatten ME (1993) Neuronal differentiation rescued by implantation of weaver granule cell precursors into wild-type cerebellar cortex. Science 260:367-369.

Gao WQ, Heintz N, Hatten ME (1991) Cerebellar granule cell neurogenesis is regulated by cell-cell interactions in vitro. Neuron 6:705715.

Gao WQ, Liu XL, Hatten ME (1992) The weaver gene encodes a nonautonomous signal for CNS neuronal differentiation. Cell 68:841854.

Gasser UE, Hatten ME (1990) CNS neurons migrate on astroglial fibers from heterotypic brain regions in vitro. Proc Natl Acad Sci USA 87:4543-4547.

Gray GE, Sanes JR (1991) Migratory paths and phenotypic choices of clonally related cells in the avian optic tectum. Neuron 6:211-225.

Gregory WA, Edmondson JC, Hatten ME, Mason CA (1988) Cytology and neuron-glial apposition of migrating cerebellar granule cells in vitro. J Neurosci 8:1728-1738.

Harrison RG (1910) The outgrowth of nerve fibers as a mode of protoplasmic movement. J Exp Zool 9:797-846.

Hatten ME (1985) Neuronal regulation of astroglial morphology and proliferation in vitro. J Cell Biol 100:384-396.

Hatten ME (1990) Riding the glial monorail: a common mechanism for glial-guided migration in different regions of the developing brain. Trends Neurosci 13:179-187.

Hatten ME (1993) The role of migration in central nervous system neuronal development. Curr Opinion Neurobiol 3:38-44.

Horan PK, Slezak SE (1989) Stable cell membrane labeling. Nature 340:167-168.

Joshi HC, Baas P, Chu DT, Heidemann SR (1986) The cytoskeleton of neurites after microtubule depolymerization. Exp Cell Res 163: 233-245.

Kuhar SG, Feng L, Vidan S, Ross ME, Hatten ME, Heintz N (1993) Changing patterns of gene expression define four stages of cerebellar granule neuron differentiation. Development 117:97-104.

Letourneau PC, Ressler AH (1983) Differences in the organization of actin in the growth cones compared with the neurites of cultured ncurons from chick cmbryos. J Cell Biol 97:963-973.
Letourneau PC, Shattuck TA, Ressler AH (1987) "Pull" and "push" in neurite elongation: observations on the effects of different concentrations of cytochalasin B and taxol. Cell Motil Cytoskel 8:193-209.

Luna EJ (1991) Molecular links between the cytoskeleton and membranes. Curr Opinion Cell Biol 3:120-126.

Luna EJ, Hitt AL (1992) Cytoskeleton-plasma membrane interactions. Science 258:955-964.

Marsh L, Letourneau PC (1984) Growth of neurites without filopodial or lamellipodial activity in the presence of cytochalasin B. J Cell Biol 99:2041-2047.

Mitchison T, Kirschner M (1988) Cytoskeletal dynamics and nerve growth. Neuron 1:761-772.

O'Rourke NA, Dailey ME, Smith SJ, McConnell SK (1992) Diverse migratory pathways in the developing cerebral cortex. Science 258: 299-302.

Persohn E, Schachner M (1987) Immunoelectron microscopic localization of the neural cell adhesion molecules $\mathrm{L} 1$ and N-CAM during postnatal development of the cerebellum. J Cell Biol 105:569-576.

Rakic P (1971) Neuron-glia relationship during granule cell migration in developing cerebellar cortex. A golgi and electronmicroscopic study in Macacus rhesus. $\mathrm{J}$ Comp Neurol 141:283-312.

Rakic P (1990) Principles of neural cell migration. Experientia 46: 882-891.

Ramon y Cajal S (1911) Histologie du systeme nerveux de l'homme et des vertebres. Reprint (Madrid: Consejo Superior de Investigaciones Cientificas, 1955). Maloine: Paris.

Rivas RJ, Burmeister DW, Goldberg DJ (1992) Rapid effects of laminin on the growth cone. Neuron 8:107-115.

Rodriguez-Boulan E, Powell SK (1992) Polarity of epithelial and neuronal cells. Annu Rev Cell Biol 8:395-427.

Sanes J (1989) Extracellular matrix molecules that influence neural development. Annu Rev Neurosci 12:491-516.

Sidman RL, Rakic P (1973) Neuronal migration with special reference to developing human brain: a review. Brain Res $62: 1-35$.

Smith SJ (1988) Neuronal cytomechanics: the actin-based motility of growth cones. Science 242:708-715.

Stossel TP (1993) On the crawling of animal cells. Science 260:10861094.

Terasaki M (1989) Fluorescent labeling of endoplasmic reticulum. Methods Cell Biol 29:125-135.

Wang K, Fcramisco JR, Ash JF (1982) Fluorescent localization of contractile proteins in tissue culture cells. Methods Enzymol 85:514562.

Weiss P (1941) Nerve patterns: the mechanics of nerve growth. Growth [Suppl] 5:163-203.

Yamamoto M, Boyer AM, Crandall JE, Edwards M, Tanaka H (1986) Distribution of stage specific neurite-associated proteins in the developing murine nervous system recognized by a monoclonal antibody. J Neurosci 6:3576-3594.

Yamamoto M, Hassinger L, Crandall JE (1990) Ultrastructural localization of stage-specific neurite-associated proteins in the developing rat cerebral and cerebellar cortices. J Neurocytol 19:619-627. 